\title{
Adolescentes autores de ato infracional e as medidas socioeducativas ${ }^{1}$
}

\author{
Joana d'Arc Cardoso dos Santos ${ }^{2}$ \\ Nilce Rodrigues de Lima Severino ${ }^{3}$ \\ Shyrlene Nunes Brandão ${ }^{4}$
}

\begin{abstract}
RESUMO - Este trabalho resulta de uma pesquisa exploratória realizada na Vara da Infância e da Juventude, do Tribunal de Justiça do DF e Territórios, no primeiro semestre de 2003, sob a responsabilidade de alunas da disciplina Psicologia Social II, sob a orientação da professora da disciplina. O objetivo foi conhecer os projetos desenvolvidos por uma seção da Vara - Seção de Medida socioeducativas - SEMSE no trabalho com adolescentes autores de ato infracional, a atuação e o papel profissional da equipe, sobretudo do psicólogo. Almejou-se ainda compreender o trabalho multidisciplinar junto aos adolescentes e a contribuição do referido órgão da Justiça à parcela da sociedade atendida no órgão: adolescentes autores de ato infracional e famílias. Realizou-se visita à instituição e entrevista semi-estruturada com uma profissional da instituição, tendo sido feita a análise qualitativa dos dados. Percebeu-se que a Seção oferece um trabalho psicossocial e pedagógico garantido pelo Estatuto da Criança e do Adolescente - ECA: busca atuar em rede com outras instituições.
\end{abstract}

Palavras-chave: violência, adolescente autor de ato infracional, medidas socioeducativas, justiça, família, parcerias, redes.

\section{Adolescents who have broken the law and socio-educating measures}

\begin{abstract}
This work is the result of an exploratory research carried out at the child and Youth Court of the Justice Court of the Federal District. The research was realized by students of Social Psychology II, under the supervision of the subject professor, during the first semester of 2003. It aimed at knowing about the projects
\end{abstract}

1 Essa pesquisa foi realizada em uma Seção da Vara da Infância e da Juventude de Brasília, tendo sido um trabalho prático da matéria Psicologia Social III.

2 Assistente social do Serviço Psicossocial Forense do TJDF. Terapeuta Familiare de Casais. Estudante do 7o. semestre de Psicologia do UniCEUB.E-mail: joanaijj@yahoo.com.br

3 Estudante do $7^{\circ}$ semestre do curso dePsicologia matutino, doUNICEUB. E-mail: nilcedf@yahoo.com.br 4 Psicóloga, Mestre em Psicologia Clínica pela UnB, Professora do UNICEUB. E-mail: shylbrandao@terra.com.br 
developed by the Socio-educating Measures Section, one of the Sections of the Child and Youth Court, which works with adolescents who have broken the law. It also aimed at comprehending the work and the role played by the staff professionals, especially of the psychologists. The objective also involved the comprehension of the multidisciplinary work with the adolescents and the verification of its contribution to the part of society the Section deals with - adolescents who have broken the law and their families. The data was analyzed through the qualitative approach, after a visit to the Section and a semi-structured interview with one professional were realized. The results showed that the Section offers a psychosocial and pedagogical work guaranteed by the Estatuto da Criança e do Adolescente ECA (Child and Youth Statute), attempting to carry out a net work with other institutions.

Key words: violence, adolescents, socio-educating measures, Justice, family, partnership/net work.

A violência é um fenômeno que tem merecido a atenção de vários estudiosos ao longo da história. Pela reflexão de Wieviorka (1997), verifica-se nos relatos históricos a constatação de que a violência não é a mesma de um período a outro. Historiadores, se propõem a caracterizar cada grande época histórica que estudam, especificando a violência. Em 1950, as lutas foram de libertação nacional, eventualmente associadas a orientações marxistas-leninistas que às vezes assumiam a feição de guerrilha, dando origem a novos regimes e a novos Estados, mas que atualmente não é mais tão importante. Isso não significa que assistimos à dissolução dos laços que associam eventualmente violência e nação, pois estes podem revestirse da idéia da violência nacionalista a qual é limitada, sendo mais étnica, ou até racial, do que propriamente nacionalista.Os anos 60 caracterizavam o início da era industrial, na França, época em que fenômenos de bandos e condutas de violência juvenil imputadas aos "apaches" ocupavam as colunas dos jornais.

Nos períodos dos anos 60 e 70 ocorreram grandes transformações na abordagem do tema, explorando a idéia de um novo paradigma, de uma nova era, caracterizando o mundo contemporâneo. Mudanças profundas estão em jogo o que é importante ressaltar as inflexões e as rupturas da violência.

Já nos anos 70 e 80, destacava-se a violência política e o terrorismo de extrema-direita, ligados à longa desestruturação das ideologias, dos regimes e dos partidos de inspiração marxista-leninista. Outro ponto foi a recusa cada vez mais artificial em perceber o declínio histórico do movimento operário regredindo em toda parte. 
De forma quase simétrica, a violência de extrema-direita, também regrediu, mantendo atividades privadas fora do controle do Estado. Nos anos 80, na Itália, por exemplo, o terrorismo de extrema-esquerda e de extrema-direita queriam acabar com o "Estado imperialista das multinacionais", outros grupos queriam criar o clima de golpe de estado com uma estratégia de tensão. A partir daí, as violências constituíram-se contra o Estado para que se protegessem as atividades econômicas de grupos mafiosos.

O declínio operário não é mais a luta contra a exploração, contra um adversário que mantém, com os atores, uma relação de dominação e sim a nãorelação social proveniente de frustrações, exclusão social e raiva social, tornando a violência objetiva e subjetiva.

Por fim, o texto de Wieviorka (1997), analisa a renovação da violência hoje, como o crescimento dos protagonistas a uma identidade étnica ou religiosa. Tais pontos poderiam aparecer como ressurgimento de violências tradicionais ou clássicas, se apenas ampliassem o efeito das condições favoráveis. Mas podese tratar de condições históricas recentes que nada têm de natural, que, segundo Jean Baudrillard (citado por Wieviorka, 1997, p. 8): "em lugar de lastimar o ressurgimento de uma violência atávica (herança psíquica), é preciso ver que a modernidade ou hipermodernidade produz esse tipo de violência dos quais o terrorismo também faz parte" (p.8).

Outro ponto relevante é levantado por Gregori, prefaciando o livro de Waiselfisz (1998), onde enfatiza a violência como uma questão global e globalizada que aparece como um dos sintomas também da modernidade.

Já Waiselfisz (1998), relata que há dificuldades na definição da violência, pela ausência de uma construção conceptual capaz de inseri-la nas relações sociais difusas e esparsas do espaço social, sendo um fenômeno com múltiplas causas. Assim, a noção de violência é ambígua, não existindo uma violência, mas uma multiplicidade de manifestações de atos violentos.

Segundo Michaud (1989), há diversas perspectivas nas ciências pelas quais se pode buscar a conceituação de violência:

- Antropologia

Relaciona a violência com os diversos aspectos na natureza humana, como a neurofisiologia, o instinto animal e a evolução. Isso, sem esquecer, a psicologia e a psicanálise. A palavra violência pressupõe juízo de valor, o que pode ser um problema na abordagem do assunto. As abordagens antropológicas preferem descartar o termo violência, dando importância a outros aspectos como a agressividade, irritabilidade e combatividade. 


\section{- Neurofisiologia}

Os organismos reagem aos estímulos do ambiente, que para eles são agressões. Selye, por exemplo, concentrou-se na análise das síndromes da adaptação dos organismos complexos que reagem ao estresse. O SAG é a reação geral do organismo atacado (modificações endócrinas, metabólicas e reações orgânicas, como febre, desmaios, etc.).

As relações entre estresse e agressividade acontecem de duas maneiras. Primeiro há uma relação com a irritabilidade quando se produz uma modificação do equilíbrio geral do organismo atacado. Segundo, a própria agressividade é uma forma de estresse.

\section{- Etologia e agressividade}

A etologia estuda o comportamento animal em seu ambiente natural. $\mathrm{O}$ desenvolvimento da agressividade é natural, o que pode ser encarado com um elemento de seleção natural, como vemos em cães e touros. A agressividade é própria do homem e também dos outros animais. Tal instinto pode ter sido adaptativo nos primeiros homens, mas depois de uma certa evolução o instinto se tornou nocivo.

\section{- Antropologia pré-histórica.}

Há 1,7 milhão de anos, houve uma ruptura do homem com o comportamento animal. Em vez de um comportamento de retraimento e fuga, tudo indica que o homem adotou um comportamento de predação e ataque. Sua agressividade conquistadora e imperialista inaugura o descobrimento e a exploração inventivos de um meio ambiente que não se limita mais a um pequeno território. A agressão acompanha a conquista, a destruição e a exploração. Neste sentido, há uma violência no próprio âmago da humanidade que anima as suas invenções, suas descobertas e sua produção de cultura.

\section{- Psicologias da agressividade}

a) A psicologia geral da agressividade busca as leis que enunciam correlações entre certos fatores determinados e as condutas agressivas. Em geral, os estudos são experimentais e estatísticos. As teorias mecanicistas, do tipo behaviorista ou neo-behaviorista, consideram os estímulos desencadeadores da agressividade e da raiva.

b) Outras teorias psicológicas insistem na importância dos modelos na aprendizagem da agressão. Há uma aprendizagem da agressividade e da violência a partir de modelos cuja carga emocional é forte. Assim, os jovens delinqüentes têm freqüientemente uma história familiar de crianças espancadas ou mártires. 


\section{- Contribuições da psicanálise}

Freud reconheceu desde cedo a importância da agressividade. Segundo ele, na vida em sociedade o homem aprendeu a transformar os instintos naturais em agressividade, essa, por sua vez, voltada contra os estrangeiros e usada como fonte de unidade para o grupo. Ao mesmo tempo, esse mesmo grupo reprime a violência dos indivíduos entre si. Essa repressão acontece, primeiro, pela coação da autoridade que gera o fenômeno da consciência, e depois é interiorizada no superego e a culpabilidade aparece como manifestação do medo que o ego tem dela. A civilização é indissociável do mal-estar da culpabilidade.

A diversidade dos fatores e a complexidade da etiologia da agressividade são tais que não há possibilidade de implantação de uma detecção das personalidades perigosas. O controle da agressividade deve ser efetuado por meio de feedback a partir de violências efetivamente produzidas.

Pode-se ainda definir violência como o fenômeno que se manifesta nas diversas esferas sociais, seja no espaço público ou privado, aprendido de forma física, psíquica ou simbólica. (Waiselfisz, 1998).

Atualmente, vários autores apontam para uma nova conceituação de violência, incluindo e nomeando como violência acontecimentos que passavam, anteriormente, por práticas costumeiras das relações sociais que tiveram mudanças na estrutura social e da concentração das atividades humanas no espaço urbano. Ampliando-se as categorias de percepção de violência, abarcando significações múltiplas. (Porto,1997, citado por Waiselfisz, 1998).

Silva Neto (2000), define o ato violento não como uma reação natural, mas sim como uma produção social, sendo um produto de contextos sócio-políticoculturais determinados. Para ele, "no ato violento há o intuito de domínio e submissão do corpo de uma pessoa ou de um corpo social, seja o ato realizado por um indivíduo, grupo social ou governos de estados nacionais." (p. 87). Pode parecer difícil imaginar o ato violento somente dentro dessa perspectiva de domínio e submissão quando no dia-a-dia presenciamos tantos atos, que qualificamos como violência como, por exemplo, quando alguém agride outra pessoa. Entretanto, o autor ressalta que não podemos confundir violência com agressão pois esta seria necessária à sobrevivência e motor de atividades básicas como sexo e alimentação. No ato violento estariam presentes sadismo e destrutividade.

A partir da perspectiva de Reich, Silva Neto (2000) clarifica a distinção entre "agressão" e "violência", dizendo que violência e desproteção seguem associadas no mundo humano, uma vez que esta sempre ocorre contra seres indefesos. Além dessa perspectiva, o autor busca correlacionar violência à noção de identidade, ou seja, a percepção de si mesmo como indivíduo singular conhecedor 
do que lhe é próprio. Ao abordar esse aspecto, diz ele que "entramos nos descaminhos da percepção de si mesmo." (p. 90). Segundo o autor, quem percebe a si mesmo como indivíduo singular, ou seja, quem tem identidade própria, verá a outra pessoa como distinta de si, como um outro em sua singularidade. No ato violento, a seu ver o outro não é visto como ser autônomo, mas como um objeto sujeito à vontade do violentador. Essa não percepção da outra pessoa como autônoma seria, para ele, uma falha na percepção da realidade ou uma falha perceptiva. E ele vai além dizendo que o fato de se atribuir uma distorção perceptiva do violentador, ou mesmo enquadrá-lo em categorias da psicopatologia, não justifica o ato de violência, cabendo à Justiça decidir sobre seu crime e não à psicologia.

Importante essa perspectiva dada por Silva Neto (2000), pois o psicólogo tem o seu papel definido mesmo no contexto judicial, tratando de autores de atos violentos ou infracionais. Ademais, o sistema jurídico mantém projetos para trabalhar essas questões, assim como outras entidades executam projetos preventivos relacionados a essa questão. O mesmo autor afirma que para a prevenção da violência por meio de programas que favoreçam o desenvolvimento humano, a psicologia lança mão de grande quantidade de métodos e técnicas construídos por psicólogos, educadores e artistas com o objetivo de ampliar o conhecimento de si mesmo. Segundo ele, a utilização desses instrumentos precisa ser pensada em função do contexto onde serão colocados em prática: "contexto escolar, de instituição correcional, terapêutico, de atividades culturais, entre outros." (p.91).

Segundo Porto (2000), a violência não pode ser analisada independente do campo social em que está inserida, sendo que suas mudanças ocorrem de acordo com a natureza do social. Além disso, a violência não é recente e sim o que a caracteriza. A violência contemporânea possui pontos diferenciados de suas formas tradicionais de manifestação. Entre os fatos ligadas a esses pontos destacam-se dois: questão de valores e questão de legitimidade. No aspecto de questão de valores, há fragmentação sociocultural e falta de uma representação unificada do social, falta também uma noção norteadora de conduta. Já no aspecto da questão da legitimidade, seria importante analisar a relação da violência com a própria legitimidade, das formas como ela é percebida e o seu próprio conteúdo. Porto (2000) cita o seguinte exemplo:

"a violência política no anos 60 e 70 buscava sua pretensão de legitimidade na própria legitimidade da causa, no objetivo que a constituía. Este conteúdo informava a representação que os atores construíam de suas práticas, a qual a representação se prestava ao autoconsumo dos protagonistas da violência, funcionando como moeda de troca, a qual buscava ampliar sua legitimidade no conjunto da sociedade, desqualificando assim os “inimigos"” (p. 195). 
Ao organizar nosso estudo para colher essa percepção, temos a preocupação de fugir de duas visões extremistas que são recorrentes quando se debate esta temática. A primeira origina-se de uma concepção do adolescente enquanto vítima de um sistema social ou então como produto do meio, sendo, portanto, a prática do delito encarada como uma estratégia de sobrevivência ou uma resposta mecânica do adolescente a uma sociedade violenta e infratora para com os seus direitos mais elementares.

Produzida com certa dose de fatalismo, essa concepção reforça a idéia do delito como "reação a um delito anterior". Teríamos, neste sentido, que sermos condescendentes para com os infratores e, ao invés de corrigir-lhes a conduta ou propor-lhes novo projeto de vida, deveríamos corrigir o meio social e exigir a reparação dos direitos violados antes de submetê-los a qualquer tipo de sanção ou pena.

Menos sofisticada na linguagem popular, a segunda visão é explicitada pela compreensão de que o adolescente infrator é um doente incorrigível, que já nasceu para fazer o mal e de que qualquer tratamento que se lhe dê poderá apenas atenuar seu perigo. Dessa perspectiva se alimentam os clamores pela pena de morte, prisão perpétua e castração química.

A expressão adolescente infrator é comumente reduzida a infrator, tornando o adjetivo mais importante que o substantivo, imprimindo um estigma irremovível.

Por estas considerações, evidenciamos nosso conceito de adolescente enquanto sujeito de direitos. Pessoa em desenvolvimento cujas garantias devem ser asseguradas com prioridade absoluta. Conceito esse que não acolhe a idéia de vítima nem de agressor, muitas vezes implícita nas práticas sociais daqueles que deveriam fazer deles sujeitos de direitos.

O tema da prática de atos infracionais por adolescentes, enquanto objeto de preocupação jurídica, não tinha uma abordagem específica até o século XIX. Seja porque a própria questão da adolescência não era colocada nos moldes sobre os quais se debate hoje, talvez pelo fato do direito fazer poucas distinções em relação a réus, delitos e penas, naquela época.

Silva Pereira (citada por Volpi, 2000), observa que a iniciativa dos Estados Unidos da América em criar no estado de Illinois o primeiro Tribunal de Menores, em 1999, espalhou-se pela Europa e influenciou a legislação brasileira, através da França. Iniciando em 1905 na Inglaterra, já em 1920 os demais países europeus haviam criado uma legislação específica (Leis de Menores) e uma administração especializada na questão dos menores (os Tribunais de Menores).

Na América Latina, influenciada pela experiência européia, o Direito e a Administração do Menor foram introduzidos em 1919 na Argentina, a partir dos 
quais os demais países da região acabaram adotando o mesmo modelo.

O Código Criminal do Império do Brasil, promulgado em 1830, abordava a temática, mas somente impedia a responsabilização criminal dos que tivessem menos de 14 anos.

A etapa do tratamento penal indiferenciado no Brasil pode ser identificada em 1890 através do primeiro Código Penal da República, que só não considerava criminoso "os menores de nove anos completos" (art. 27, $\S 1^{\circ}$ ) ou aqueles que, sendo maiores de nove e menores de 14 anos houvessem agido sem discernimento (art. 27, $\S 2^{\circ}$ ).

Vale lembrar que diante da inexistência de instituições especializadas para o atendimento dos menores de idade, os mesmos, quando condenados, eram inseridos no sistema carcerário dos adultos, sofrendo os abusos decorrentes desta promiscuidade.

Em 1902, Mello Mattos propõe para o Brasil um Projeto de Proteção ao Menor que é transformado em Lei no ano de 1926, sendo promulgada em 12 de outubro de 1927 o Código de Menores, dando início a uma longa etapa tutelar.

As Leis 4655 de 1965; 5258 de 1967 e 5439 de 1969 ampliaram e modificaram dispositivos legais mas mantiveram a base ideológica que deu origem em 1979 a um Código de Menores reformado e que se constituiu na peça jurídica mais contundente de explicitação da divisão de infância por categorias arbitrárias e excludentes.

No governo de Getúlio Vargas, o Estado cria o Departamento Nacional da Criança (1940), com o objetivo de coordenar em âmbito nacional as atividades de atenção à infância. Com o intuito de desenvolver atividade de amparo aos "menores desvalidos e infratores" é criado em 1941 o Serviço de Assistência ao Menor (SAM).

A promiscuidade, a violência, o tratamento desumano, a atuação repressiva dos "monitores", as grades e muros altos, o distanciamento da população através da organização interna das instituições garantia a arbitrariedade e o desconhecimento por parte da população do que acontecia "intramuros".

No início da década de 60, já era forte na sociedade a convicção de que o SAM era uma escola do crime. Os adolescentes que de lá saiam não tinham outra opção senão retribuir à enorme carga de violência a que foram submetidos. $\mathrm{Na}$ esteira das Reformas de Base buscava-se a produção de uma política de atenção à infância que lhes desse um tratamento mais digno.

O golpe militar de 1964 abortou o SAM que foi substituído por uma Política Nacional de Bem-Estar do Menor (PNBEM), que deu continuidade ao tratamento desumano. Sob novas fachadas, os internatos continuaram funcionando e 
constituíram-se numa rede nacional de Fundações Estaduais de Bem-Estar do Menor (FEBEM).

Com o processo de abertura, o fim do regime militar e o ressurgimento dos movimentos populares, ganha força o movimento em defesa dos direitos do "menor". Estado, Igreja e sociedade debatiam-se entre esses dois modelos, conseguindo como resultado a estigmatização de crianças e adolescentes sob o rótulo de menores, a desaprovação da sociedade, a ineficiência das ações, o desrespeito à dignidade humana e aos direitos mais fundamentais.

O Código de Menores, Lei n. ${ }^{\circ} 6697$ de 1979, na análise de grande parte das instituições que atuavam na área representava a legitimação da violação dos direitos. Dentro do nosso campo de interesse é importante destacar que o caráter mais perverso desse Código de Menores e da sua fundante Doutrina da Situação Irregular estava na homogeneização da categoria "menores" onde adolescentes autores de infrações penais e adolescentes vítimas de todo tipo de abusos e explorações eram tratados igualmente por uma ação concreta de caráter penal denominada, de forma eufêmica, de tutelar.

Ao mergulharem na realidade da rua esses menores percebiam um mundo absolutamente diverso: sem horários, com valores, linguagens e diversões diferentes, com novidades e dinamismo e com outros padrões morais. Estar na rua para os meninos significava estar no seu campo de domínio, com os seus códigos, suas estratégias de sobrevivência, seus aliados e inimigos, enfim sua "casa". Mas significava também estar exposto a um conjunto de interesses e de exploração que vai desde o tráfico de drogas até o abuso sexual. Mesmo sobrevivendo nesse paradoxo, parecia ser mais suportável do que ter que conviver na favela com núcleos familiares desmontados, famintos, explorados, e por isso violentos. "Os pais apanham da vida e os filhos apanham dos pais" e vão às ruas, conforme diz Volpi (2000, p. 16).

Surgem assim, por todo o Brasil, diferentes iniciativas de atendimento aos meninos e meninas de rua, produzindo uma nova metodologia de trabalho que passou a ser conhecida como Educação Social de Rua. Surgiram a partir daí, associações de engraxates, cooperativas de picolezeiros, grupos comunitários e muitas outras iniciativas.

No início da década de 80 surge o projeto Alternativas de Atendimentos aos Meninos e Meninas de Rua, com o objetivo de colocar em contato essas diferentes experiências, promover o intercâmbio de idéias, analisar processos e somar esforços no atendimento a essa população.

Em 1985, o Movimento Nacional dos Meninos e Meninas de Rua nasce como espaço de articulação dos programas de atendimento e dos educadores 
comprometidos com esta questão e com a organização dos meninos e meninas de rua.

A Constituição de 1988 trouxe grandes avanços. A Assembléia Constituinte inseriu o artigo 227, com base na Doutrina de Proteção Integral originada na proposta de Convenção Nacional Sobre Direitos da Criança da ONU. Os três princípios fundamentais da convenção são: 1) o conceito de criança enquanto sujeito de direitos e que tem condições de participar das decisões que lhe dizem respeito; 2) o princípio do interesse superior da criança, isto é, que os direitos da criança devem estar acima de qualquer outro interesse da sociedade; 3) o princípio da indivisibilidade dos direitos da criança, ou seja, não se trata de assegurar apenas alguns direitos e sim todos.

Depois de aprovada a Constituição Brasileira, começa o processo de regulamentação por meio de leis complementares. É aí que surge o Estatuto da Criança e do Adolescente, que repudia o termo "menor" de caráter estigmatizante e discriminador, muda-se a concepção de infância e adolescência entendendoos como cidadãos, sujeitos de direitos, que precisam ser considerados como pessoas em desenvolvimento e tratados como prioridade absoluta.

Não obstante os avanços da legislação atual, é fato que entre o direito assegurado na lei e o realizado no cotidiano ainda existe uma enorme distância.

Segundo Volpi (2000), no que se refere às medidas aplicáveis àqueles que têm seus direitos violados e ameaçados ou ainda àqueles que ameaçam ou violem direitos de outrem, a resposta social determinada pelo novo paradigma legal não rompe no seu sentido mais profundo, com uma perspectiva funcionalista. Tanto os programas de proteção aplicados aos negligenciados, maltratados, abusados, desrespeitados e que têm seus direitos negados quanto as medidas sócio-educativas aplicadas aos descumpridores da lei, constituem-se em alternativas de socialização tradicional, cujas obrigações reduzem-se à integração familiar, à colocação profissional, à frequiência à escola e ao desenvolvimento de atividades esportivas e culturais. As categorias usualmente adotadas enquanto estratégias são, na maioria das vezes, explicitadas por expressões com o prefixo "re" como que para firmar a idéia de retorno a uma situação anterior de normalidade. Recolocação familiar, reestruturação da família, reeducação, re-socialização, recomposição dos vínculos familiares, reajuste de conduta, e outros tipos de expressões que passam a idéia de voltar a ser. Há por trás dessas expressões uma concepção formal de que a sociedade é um todo harmônico, cujo equilíbrio se mantêm pelo cumprimento dos papéis e expectativas que lhe são atribuídos pela cultura, pela religião e pelos chamados aparelhos ideológicos do Estado. (Althusser, 1974).

A experiência da privação de liberdade, quando observada pela percepção de quem a sofreu, revela toda a sua ambigüidade e contradição, constituindo-se 
em um misto de bem e mal; castigo e oportunidade; alienação e reflexão, cujo balanço final está longe de ser alcançado, uma vez que as contradições da sociedade nunca serão isoladas no interior de qualquer sistema por mais asséptico que ele seja. A instituição é um processo dialético, pois ao mesmo tempo em que determina demanda e condiciona a vida humana, é construída, interpretada e desconstruída historicamente pelo ser humano.

Para Volpi (2000), há um desequilíbrio na compreensão e interpretação da realidade decorrente da supervalorização da conduta humana (individual ou coletiva), tanto na produção social quanto das instituições sociais. Nesse sentido, negligencia-se que: "A sociedade é um produto humano. A sociedade é uma realidade objetiva. O homem é um produto social”. (Berger e Luckmann, 1999, citado por Volpi, 2000, p.46).

Portanto, adotamos um conceito interativo do delito, proposto por Volpi (2000), concluindo que ele é produzido socialmente e reinterpretado individualmente para ser reconstruído socialmente num processo dialético permanente. Sendo que algo que seja delito hoje pode não sê-lo no futuro e algo que foi delito no passado pode não ser no presente.

Ao abordar a questão da violência a partir da perspectiva de um ato infracional, sob o prisma desse último conceito apresentado, seria igualmente fundamental se considerar o contexto em que o trabalho será desenvolvido: em âmbito de reclusão ou em meio aberto. Além disso, será fundamental entender-se a visão de uma abordagem socioeducativa, tanto juridicamente, quanto do ponto de vista psicossocial. O trabalho que apresentaremos trata-se de um projeto que executa as medidas socioeducativas dentro de uma abordagem psicossocial aos adolescentes autores de atos infracionais, na Vara da Infância e da Juventude de Brasília, na Seção denominada SEMSE - Seção de Execução de Medidas Sócio-Educativas.

Antes de tratarmos propriamente do projeto desenvolvido pela SEMSE consideramos importante discorrer brevemente sobre os adolescentes em conflito com a lei. Nesse sentido, a relação entre violência e o ato infracional é bastante estreita. Segundo Magagnin (1999), atualmente tem-se verificado "um aumento significativo da violência por parte dos jovens" (p. 44). Tem-se notícia, por meio da mídia, de adolescentes cometendo assassinatos, violências nas escolas, violências de jovens envolvidos em crimes organizados, violências de gangues de lutadores, dentre outras. Estão aí envolvidos adolescentes de diferentes classes e grupos sociais e, segundo a autora, isso leva a pensar numa banalização da violência por parte dos jovens.

Segundo Magagnin (1999), a literatura especializada traz abordagens gerais que procuram explicar o comportamento violento dos jovens, considerando-se, sobretudo, a rebeldia e a turbulência como uma singularidade da adolescência 
em um processo mais amplo de desenvolvimento. Outras abordagens, buscam explicações mais voltadas para os aspectos sócio-culturais destes sub-grupos em especificidades de determinados contextos juvenis. Em sua pesquisa, essa autora discute a violência praticada por adolescentes pobres e pelos de classe média, separadamente, por considerar que esses jovens têm espaços, condições e oportunidades distintas para o seu desenvolvimento, assim como valores culturais diferentes.

Magagnin (1999), diz que em Brasília, assim como na maior parte dos grandes centros urbanos, a questão da violência coloca-se como um dos principais problemas sociais. Contudo, ela recorre às idéias de Machado (1997), que refere serem difundidas representações sobre Brasília como uma cidade que tem baixos índices de violência, se comparada com outras cidades pelo fato de ser uma cidade nova e possuir características urbanas diferenciadas.

A esse respeito, pesquisa realizada pela Secretaria de Ação Social em 2000 mostrou que $85,7 \%$ dos adolescentes autores de ato infracional eram brasilienses e os demais oriundos do nordeste, centro-oeste e norte. Quanto à motivação para a prática de atos delituosos, a maior motivação que levou à internação foi "gastos pessoais" $(33,3 \%)$ e em seguida aparece a "compra de droga" $(29 \%)$. O delito mais frequientemente motivador de internação foi o roubo $(32,1 \%)$, seguido de homicídio $(26,2 \%)$ e latrocínio $(14,4 \%)$. A soma desses três tipos de infração chega a 70,6\% dos motivos das internações. Além disso, $43 \%$ dos jovens internos fazem parte de gangues o que facilmente pode ser correlacionado com a violência. Dados estatísticos da SEMSE mostram que, em 1999, 1167 adolescentes com medidas socioeducativas foram atendidos no setor e foram encaminhados aos órgãos executores. Estes adolescentes, receberam medidas socioeducativas como: Prestação de Serviços à Comunidade, Liberdade Assistida, Semiliberdade e Internação.

Frente a esse tema, o presente estudo buscou conhecer os projetos desenvolvidos pela Seção de Medidas Socioeducativas - SEMSE, junto aos adolescentes autores de ato infracional, buscando entender a atuação profissional, sobretudo do psicólogo, nessa equipe. Com isso, almejou-se compreender o papel profissional deste, a atuação da equipe multidisciplinar junto aos adolescentes, bem como a contribuição que esse órgão público oferece a essa parcela da sociedade, qual seja: os adolescentes autores de ato infracional e suas famílias. 


\section{Metodologia}

\section{Instituição}

A escolha da instituição visitada se deu pelo interesse do grupo de estudantes da disciplina Psicologia Social II em conhecer os projetos da Seção de Medidas Socioeducativas, obtendo uma compreensão das ações dos profissionais da área psicossocial. O interesse resultou ainda da intenção de conhecer a existência de ações concretas divulgadas pela imprensa falada e escrita e que devem ser campo conhecido de um profissional da Psicologia Social.

\section{Participante}

A escolha da profissional entrevistada ocorreu em função do seu cargo. Por ser a supervisora da Seção, considerou-se que seria a pessoa que reuniria mais conhecimentos acerca do trabalho desenvolvido na SEMSE.

\section{Instrumento}

Foi utilizada a técnica de entrevista semi-estruturada.

\section{Procedimento}

1- Foi feito preliminarmente um contato telefônico com a supervisora da Seção de Medidas Socioeducativas, solicitando uma entrevista pessoalmente, oportunidade em que se explicou o objetivo da mesma;

2- Foi marcada a data e local da entrevista também por telefone;

3- Foi elaborado um roteiro de entrevista com doze perguntas relacionadas às medidas, aos projetos, à equipe, à família e aos adolescentes (Anexo I);

4- Entrevistou-se a supervisora da Seção, cuja entrevista foi gravada;

5- Procedeu-se à degravação;

6- Transcreveram-se as idéias principais, identificando-se as zonas de sentido;

7- Levantaram-se os temas a partir das zonas de sentido e releitura do texto da entrevista;

8- Elaborou-se a análise qualitativa dos dados à luz da psicologia social, com base na teoria que trata da questão da violência.

\section{Resultados e Discussão}

A análise dos dados foi realizada com base na proposta interpretativa de González Rey $(1997 ; 1999)$. Como foi realizada apenas uma aproximação inicial da proposta do autor, e devido ao curto período de realização da pesquisa, não 
foi uma interpretação profunda dos dados, no entanto a análise feita já possibilita algumas reflexões acerca do tema.

Inicialmente, a entrevista foi transcrita, o texto foi lido, realizando-se um levantamento de indicadores, conforme a proposta de González Rey (1997; 1999). Segundo o autor, "um indicador representa uma construção capaz de produzir um significado através da relação que o investigador estabelece entre um conjunto de elementos que, dentro do contexto do sujeito estudado, permitem formular uma hipótese que não guarda relação direta com o conteúdo explícito de nenhum dos elementos tomados separadamente". (González Rey, 1999, pp.114 e 115).

Indicadores semelhantes foram agrupados, obtendo-se grupos temáticos, equivalentes ao que Minayo (1996) chama de "Corpus", que sintetizavam as principais idéias apresentadas na entrevista. Em seguida foi realizada a interpretação desses grupos temáticos, compreendendo interpretação como um momento de construção teórica, o diálogo do pesquisador com o material obtido (González Rey, 1999).

Desta forma, foi possível a construção de doze eixos temáticos: Busca de manter um discurso coerente com o direito de cidadania do adolescente atendido pela SEMSE; as gradações dos delitos/ato infracionais e suas respectivas abordagens; privação de liberdade/internação: a medida mais drástica; a importância atribuída à família; o papel dos componentes do sistema jurídico; reparação - ressarcindo os prejuízos causados; parcerias/redes - possibilidades de diminuir as dificuldades; as dificuldades institucionais e a busca de alternativas; drogas - uma questão de saúde; criação de projetos para atendimento à demanda; o preconceito como um dificultador de mudanças; reincidência - o resultado do sistema emperrado ou o resultado da não mudança.

\section{Busca em manter um discurso coerente com o direito de cidadania do adolescente atendido pela SEMSE}

Os temas mostraram que existe uma busca por profissionais da Seção de Medidas Socioeducativas - SEMSE de abordar a questão da violência, presente no ato infracional, dentro de uma visão onde não há o extremismo de tratar o adolescente como vítima do sistema social ou como um doente incorrigível, de outra parte, conforme expusemos inicialmente neste trabalho. Ao invés disso, ele é tratado como sujeito com direito de cidadania . Nesse sentido, ele recebe a denominação de autor de ato infracional, pois é responsável por seus atos, sujeito de direitos e deveres.

Esta visão tem sua história, na medida em que, conforme dissemos 
anteriormente, o tema da prática de atos infracionais por adolescentes, enquanto objeto de preocupação jurídica, não tinha uma abordagem específica até o século XIX. Isso decorria do fato de até então, a questão da adolescência não ser colocada nos moldes do debate atual, além de que o direito fazia poucas distinções em relação a réus, delitos e penas. No Brasil, essa construção passou por várias etapas em torno das leis até chegar ao Estatuto da Criança e do Adolescente - ECA. Nesse sentido, a despeito de todas as críticas, parece que esta lei influenciou nessa visão diferenciada contribuindo, realmente, para que o adolescente passasse a ser visto como cidadão, uma vez que a lei usa a terminologia "adolescente autor de ato infracional" o que contribui para uma mudança de postura. Na entrevista aparecem frases como: "O adolescente tem uma liberdade de ir e vir, tem direito, pela lei, de estudar, de sair para trabalhar, de conseguir emprego."; "há também um psicólogo, um assistente social que dá apoio psicossocial, fazendo atendimentos.", "É atendido tanto o adolescente, autor de ato infracional, quanto o adolescente vítima de violência em qualquer nível". Talvez um estudo específico sobre esse tema pudesse apontar para essa contribuição ou não da lei no sentido de mudar a visão sobre o adolescente na prática. Isso seria importante na medida em que a lei estaria cumprindo um papel no sentido de mudar algo bastante criticado que é a rotulação estigmatizante, onde a expressão adolescente infrator é comumente reduzida a infrator, tornando o adjetivo mais importante que o substantivo, imprimindo um estigma irremovível.

\section{As gradações dos delitos/ato infracionais e suas respectivas abordagens}

Diante de todas as evoluções relacionadas à questão, evoluiu também o conceito de delito/ato infracional, na medida em que tem sido adotado um conceito interativo do delito, conforme proposto por Volpi (2000). Este autor mostra que tal conceito é produzido socialmente e reinterpretado individualmente para ser reconstruído socialmente num processo dialético permanente. Assim, algo que seja delito hoje pode não sê-lo no futuro e algo que foi delito no passado pode não ser no presente. Essa parece ser a realidade histórica que vivemos em torno desse tema. Na entrevista são citados delitos como: Homicídio, latrocínio e furto (delitos que aparecem no perfil levantado pela Secretaria de Ação Social em 2000 como os maiores motivadores de internação). De fato, a entrevistada cita-os também como sendo de alta incidência, os quais conduziriam o adolescente da Delegacia da Criança e do Adolescente - DCA à Vara da Infância e da Juventude - VIJ. 


\section{Privação de liberdade/internação: a medida mais drástica}

Depreende-se da entrevista, que após todo o trajeto do adolescente autor de ato infracional, desde a DCA, passando pelo Promotor de Justiça e Juiz até chegar à SEMSE, define-se a medida e o trabalho a ser desenvolvido diante da gravidade do ato. Assim, por exemplo, afirma a entrevistada: "se cometeu um furto, com infração leve e esse promotor entende que esse adolescente pode ficar em meio aberto, poderá fazer um acordo na própria oitiva ${ }^{5}$. Entretanto, nos casos de maior gravidade, o adolescente já é encaminhado para a unidade de internação. Isto, além de mostrar as gradações de aplicação das medidas, previstas pela lei, pode aproximar-se também de uma ampliação das categorias de percepção de violência, abarcando múltiplas significações conforme expõe Porto (citado por Weiselfisz, 1998).

Um aspecto interessante é se ver que as medidas socioeducativas estão relacionadas ao que diz Bucher (1992): "as ações educativas e afetivas são parâmetros não só de aceitação da autoridade da lei, mas também para a questão do equilíbrio da identidade do indivíduo que vai se formar dentro desse contexto." (p. 478). Assim, por exemplo, quando o adolescente evade do Centro de Atendimento Juvenil Especializado - CAJE (medida de internação) ou mesmo das unidades de semi-liberdade, pode não estar aceitando a autoridade de nenhuma das instâncias desde os educadores, os profissionais da Secretaria de Ação Social e da SEMSE, até o Juiz. Em relação ao CAJE a entrevistada usa expressões como: "Medidas privativas de liberdade, privado de liberdade, unidade de internação", o que segura muito o CAJE é a punição ainda", "Em relação à internação, principalmente conseguir pelo menos restringir um pouco essa lotação, chegar ao número ideal, porque qualquer projeto pedagógico falha”. Em nenhum momento se vê a utilização de expressões como re-socialização, reajuste de conduta ou outros termos funcionalistas citados por Volpi (2000), ao criticar as medidas aplicáveis e os programas de proteção.

Isso resulta numa das dificuldades encontradas na execução das ações sócioeducativas onde há um contra-senso, ou mesmo o paradoxo representado pela dimensão de proteção ou reeducação, de um lado, e do controle e punição do outro, revelando a dialética das relações institucionais. Isso acaba nos remetendo à dimensão do papel institucional, sobre a compreensão de Lane (1981), ao analisar o processo grupal sob a ótica do materialismo dialético. Ela mostra que como todo grupo existe dentro de uma instituição, é fundamental a análise do tipo de inserção do grupo na instituição: se foi criado pela instituição, com que objetivo

5 Oitiva-ato jurídico em que, nesse caso, o adolescente será ouvido. 
e funções; se surgiu espontaneamente, em que condições surgiu - para manutenção ou contestação da estrutura institucional. Nesse sentido, as dificuldades muitas vezes podem estar relacionadas a esta questão, uma vez que na realidade dos internos ou mesmo dos adolescentes em semi-liberdade eles acabam se tornando membros de grupos ("famílias"), pois é impossível não se relacionar, afiliações que ocorrem aleatoriamente ou por afinidades ao ingressarem na instituição e isso, os levará a uma forma própria de se organizarem. Em geral, o que se vê é uma organização no sentido de contestar a ordem estabelecida.

Em se tratando ainda da internação seria importante lembrar as palavras de Volpi (2000):

"A experiência de privação de liberdade, quando observada pela percepção de quem a sofreu, revela toda a sua ambigüidade e contradição, constituindo-se num misto de bem e mal; castigo e oportunidade, alienação e reflexão, cujo balanço final está longe de ser alcançado, uma vez que as contradições da sociedade nunca serão isoladas no interior de qualquer sistema por mais asséptico que ele seja." ( p. 41).

\section{A importância atribuída à família}

Percebeu-se, pela fala da entrevistada, que a atuação profissional busca sair da causalidade linear vendo o adolescente numa perspectiva circular, conforme refere Bucher (1992). Isso, aparece quando ela fala: "As famílias participaram ativamente, ..."; "não há rejeição da família, mas há uma dificuldade de lidar com ele, ..." E, em se tratando de família, seria fundamental frisar-se outros momentos em que aparecem as referências a ela: "Responsável; família; eixo - família; adolescente com a família"; "As famílias participam ativamente"; "A família desde o início é chamada a participar de todos os momentos”; “...na prestação de serviços, desde a primeira entrevista até todos os contatos que mantivemos, estamos sempre convidando, chamando a família, discutindo com os pais".

Volpi (2000), em seu estudo também se referiu a esse tema: "Essa família é a maior retaguarda do adolescente no período de privação de liberdade. Foi ela quem o apoiou no período mais complexo de sua vida." (p. 102). Portanto, vê-se a importância da parceria família - instituição no trabalho com esses adolescentes.

Reis (em Lane, 1997), também apóia as idéias de Volpi (2000):

"O que não pode ser negado é a importância da família tanto ao nível das relações sociais, quanto ao nível da vida emocional de seus membros. É a família, mediadora entre o indivíduo e a sociedade. É a formadora da nossa primeira identidade social." 
Sendo assim, a presença e o acompanhamento da família desse adolescente terá um papel fundamental visto que ele está em fase de formação, de introjeção de valores sociais, de regras impostas e aceitas pela sociedade. É inegável, portanto, o papel que essa família vai exercer na vida desse adolescente em conflito com a lei.

Esse papel da família é ainda frisado por Pakman (1992), que ressalta:

"as famílias que encontram o ritmo de sua vida cotidiana marcado pela pobreza e a violência costumam habitar uma fronteira cuja micropolítica inclui interações com uma multiplicidade de agências, instituições, sistema, que se tornam parte integral de sua vida cotidiana, enquanto se encontram expostos a uma condição marginal com respeito a outras instituições e sistemas que pontuam a vida cotidiana de outros setores populacionais. “(p.9).

O contato que a família vai manter com a instituição de internação, a sua parceria com ela, o significado que esta adquire para o sistema familiar será crucial para o resgate dos direitos de cidadania não só do adolescente como de todo o grupo familiar. E não é só esta instituição de internação que está em estreito contato com o sistema familiar, é também a escola, os Centros de Desenvolvimento Social - CDS, as casas de semiliberdade, os Centros de Saúde. Muitas vezes, essas agências sociais não oferecem aquilo que essa família precisa, não atendem sua demanda, por vícios e carências do próprio sistema social. Ė exatamente, aí nesse vácuo do não atendimento que muitas vezes, a família marginalizada da sociedade, encontra outros meios de se inserir e ter acesso ao direito que lhe falta, como, por exemplo, infringindo as normas sociais, cometendo delitos.

Nesse sistema jurídico especialmente, isso é bastante presente e, pode-se localizar claramente os momentos em que essas famílias se vêem em uma condição marginal. Entretanto, na entrevista aparece uma confirmação da importância da família, mas ao mesmo tempo as dificuldades para se manter um trabalho efetivo com ela: "Temos um instrumental para nos favorecer nesta conversa com o adolescente e a família. Essa conversa tem que ser rápida, de no máximo 1 hora com cada adolescente, porque senão, não conseguimos atender à demanda." Então, percebe-se o quanto a pressão da demanda acaba por dificultar as ações, já que poucos profissionais devem atender a muitos adolescentes e família em curto espaço de tempo.

\section{O papel dos componentes do sistema jurídico}

Para controlar a organização que surge nas unidades e, ao mesmo tempo, se manter o papel da instituição, a lei é aplicada pela pessoa do Juiz que impõe limites, exercendo seu papel de autoridade. Contudo, a entrevistada mostra uma 
atuação do Juiz bastante dividida com os vários profissionais da Vara. O adolescente passaria pelo promotor, onde junto com seu responsável poderia ter, inclusive, a remissão do seu ato infracional. Ele passaria também pela atuação do profissional (Assistente Social ou Psicólogo). Portanto, há uma visão mais abrangente onde o juiz funciona, conforme diz Bucher (1992), a partir da assessoria dos profissionais especializados. Então, o Juiz tem outras informações para embasar sua decisão, pois há a atuação conjunta de todo o sistema jurídico.

Nesse aspecto, aparece na entrevista: “...o caminho é este: sai da delegacia, vem para o cartório da Vara da Infância, é encaminhado para o Ministério Público ....Posteriormente, esse processo subirá para o Juiz a fim de definir a sentença".

Curioso observar que a entrevistada não se refere, nesse trajeto seguido pelo adolescente, ao momento em que ele vai para a SEMSE. Contudo, sabe-se que a ação dessa equipe se dá em dois momentos diferentes quando, na entrevista, ela se refere aos projetos: "o atendimento em plantão" e ao acompanhamento das sete medidas socioeducativas após a decisão judicial. Assim, é possível perceberse a importância dessa equipe multidisciplinar quando ela fala não só da sua composição, como também ressalta: “...é difícil até separar a atuação do profissional, por que tudo está integrado." Outros projetos citados pela entrevistada para atuação junto ao adolescente são: "Projeto de prestação de serviço à comunidade", "projeto dentro da pesquisa" e "projeto de fiscalização".

\section{Reparação - ressarcindo os prejuízos causados}

Diante da análise acima, pode-se questionar, como exigir, reparação, que é uma das medidas socioeducativas, num contexto em que os sujeitos que praticam os atos infracionais são excluídos de benefícios sociais que por lei teriam direito? Seria essa medida realmente educativa, se não houver mudanças estruturais? Ficamos pensando quão árduo é o trabalho de um profissional que precisa lutar diariamente com todas essas contradições. Conhecer de perto essa realidade de atuação de psicólogo faz levantar reflexões como esta e faz pensar em quão criativo, corajoso e persistente deve ser um profissional dessa área.

\section{Parcerias/redes - possibilidades de diminuir as dificuldades}

Em socorro à dificuldade relacionada a uma desproporção entre número de profissionais e a demanda, e mesmo a necessidade de se realizar trabalho com as famílias, o que é visto como importante, a equipe buscou formar redes de atendimento: "As famílias participaram ativamente, mas dependemos dessas parcerias externas." Contudo, essas parcerias foram pontuais e hoje, a equipe 
não se acha em condições de dar andamento nessas atuações sem o apoio dos parceiros, representados pelas universidades.

Em relação a redes, Cinnanti (1997), diz: “A metodologia da prática de redes sociais promove a integração e a complementaridade entre os diferentes seguimentos envolvidos com a questão. A prática de redes atua como instrumento de mobilização e de integração que confronta o processo de marginalização e de exclusão social" (p.76). Assim, não é possível negar a validade de um trabalho dessa natureza envolvendo essas famílias.

Ainda acrescenta Cinnanti (1997):

"Para fazer frente a toda a complexidade do universo adolescente, do contexto sociofamiliar, da condição de baixa renda, da situação de rua e das dependências químicas, é preciso conjugar conhecimentos de áreas diversas. É preciso transpor os muros entre as disciplinas e buscar a sua integração, num verdadeiro exercício de transdisciplinaridade, ou seja, de construção de redes entre as diversas áreas do saber" (pp. 75/76).

\section{As dificuldades institucionais e a busca de alternativas}

Para além das dificuldades encontradas em termos da falta de pessoal, parece que a equipe da SEMSE tem buscado caminhos como este no sentido de alcançar um trabalho de qualidade.

Aparecem ainda como dificuldades, aquelas relacionadas ao trabalho conjunto com a Secretaria de Ação Social onde se registrou relatos na entrevista tais como: "A secretaria tem inúmeras dificuldades"; "quadro reduzido de servidores; "parcos recursos para execução e deixa muito a desejar"; "há muitas dificuldades também porque o CAJE... "o CAJE está sempre com lotação maior do que o que deveria"; "impossibilidade de dar uma certa dignidade a quem está lá dentro." Nesse sentido, Werthein (2000), expressa:

"Há, todavia, um ponto consensual entre jovens e policiais: o CAJE é uma instituição onde o resultado da intervenção judicial, mais que inócuo e ineficaz, é efetivamente negativo, tornando um mito a reintegração dos infratores na sociedade. Os relatos de ambos coincidem na crítica à instituição que, para funcionar, necessitaria de um reordenamento institucional.” (p. 55).

Assim, Waiselfisz (1998), mostra que: No Brasil não existe uma tradição de políticas públicas destinadas especificamente aos jovens. Os programas para a juventude são em geral incorporados e atrelados àqueles voltados às crianças. Além disso, eles estão centrados, sobretudo nas classes populares e partem de uma visão de que o jovem pertence a um grupo em "situação de risco". Sem políticas 
sérias, portanto, nesse sentido, resta difícil superar as contradições e as dificuldades inerentes ao sistema. Isso reflete as idéias de Demo (1991), acerca da assistência social como direito de cidadania.

A respeito desse tema, Werthein (2000), apresenta as seguintes idéias:

"Também encontramos descaminhos no âmbito institucional. Pela própria condição sócio-econômica (cerca de $43 \%$ das famílias são carentes, ou seja, têm renda de até 2 salários mínimos), essas crianças não conseguem fácil acesso aos serviços das políticas de saúde, cultura, esporte, lazer entre outros." (p. 76).

Sobre essas dificuldades relacionadas à Secretaria de Ação Social, mais uma vez entra o papel da lei, com o intuito de corrigir as falhas, por meio da fiscalização prevista no ECA. Essa fiscalização é executada pela SEMSE junto aos órgãos da Secretaria e tem propiciado um espaço para criação de parcerias, mesmo que também isso seja um contra-senso, conforme já dissemos anteriormente, pois a partir da fiscalização, se tenta fazer um trabalho integrado que leve à melhoria da qualidade de atendimento na unidade de internação ou mesmo de semi-liberdade. Assim, por exemplo, aparece na entrevista: "Apoiar o órgão de execução, estabelecendo parcerias." Percebe-se aqui, a existência de uma hierarquia, na medida em que um órgão é executor e outro é fiscalizador. E ressalta: "Entendemos que temos um papel de articulação também de levantar as dificuldades e apoiar o órgão de execução, estabelecendo parcerias, correndo atrás da integração de outras instituições ..." Apesar desse esforço, entende-se que essa pretensão pode ser dificultada diferença de poderes institucionais. Sabe-se que a parceria e formação de redes pressupõem soma de saberes, troca e reconhecimento da capacidade de contribuição do outro, é uma construção que pressupõe complementaridade. Essa prática, por si só, entre dois níveis diferenciados (órgão fiscalizar e executor), deve resultar em mais uma dificuldade para a equipe da SEMSE e da Secretaria.

\section{Drogas - uma questão de saúde; criação de projetos para atendimento à demanda}

A situação de excluídos piora ainda mais quando esses jovens passam a se envolver com drogas. Muitos deles já chegam à SEMSE em função de atos infracionais relacionados a isso. A respeito desse tema, Waiselfisz (1998), pontua que: "É, no mínimo, arriscado estabelecer relação mecânica de causalidade entre consumo de drogas e violência. O que certamente ocorre (e os jornais costumam tratar disso cotidianamente) é uma relação direta entre violência e comercialização de drogas" (p.35). Entretanto, em se tratando dos casos em referência, tem sido constatada a ligação. Essas considerações são de extrema importância, segundo 
Waiselfisz (1998), para situar a problemática do consumo das drogas: "Na maioria das vezes, os jovens não associam violência a consumo de drogas. Entre os jovens dependentes (...) prevalece uma visão justamente oposta". (p. 35, 36).

Em relação à relação entre violência e droga, a entrevistada refere que eles são "pegos cometendo furtos, um atrás do outro" e que necessitariam de uma "medida de proteção na área da saúde e não de medidas socioeducativas". Entretanto, pelas incongruências do sistema, as primeiras acabam não sendo aplicadas pelo fato de não serem obrigatórias e muitas vezes a família ou o adolescente não cumpri-las. Assim, parece que se trabalha com a transformação da obrigação em demanda, na tentativa de se fazer ao menos o mínimo por esses adolescentes e pela sua família.

Importante refletir em que medida a família considera que seria necessário ela própria se submeter a um tratamento quando, muitas vezes, a questão é vista de forma linear e o problema estaria, portanto, no adolescente. Waiselfisz (1998), expressa que para os pais, a relação com filhos dependentes químicos é "muito difícil, um fardo". Os pais relatam que há mudanças do comportamento dos filhos quando começam a usar drogas. Há queda do rendimento escolar e atitudes agressivas e violentas.

Acrescenta ainda Waiselfisz (1998), que pais e filhos passam a ter um diálogo limitado, difícil e penoso. Para enfrentar, na família, os problemas decorrentes do consumo de drogas, alguns pais chegam a colocar os filhos para fora de casa, ou a adotar outras medidas extremas. Com relação a isso, já se referiu que a entrevistada mostra a perspectiva da dificuldade dos pais em lidar com seus filhos sobretudo quando se trata de jovens que fazem uso de drogas.

Para completar, a dificuldade de inserir-se, ou mesmo manter-se, no ensino formal parece agravar esse quadro. Uma questão colocada pela entrevistada diz respeito à necessidade do órgão executivo (Secretaria de Ação Social) manter um trabalho junto ao eixo-escola o que acaba não sendo realizado. Mais uma vez a importância da parceria e formação de redes aparece.

É o que revela o trabalho de Waiselfisz (1998): "Nos grupos focais, os jovens revelam sua descrença nas instituições públicas em razão da corrupção e falta de ética existentes." (p.99).

Pensando na ética seria fundamental analisar-se o que diz Freitag (citada por Waiselfisz, 1998):

"A questão da moralidade é uma questão de 'como agir'? A moralidade tem a ver com a 'ação'; como o sujeito relaciona sua ação com a dos outros. Tem também a ver com critérios capazes de julgar o justo e o injusto, o bem e o mal, e explicar a causa da ação, ou seja, o que levaria o sujeito a agir dessa forma. As 
idéias de princípios, valores e julgamentos considerados corretos entre moralidade e normatividade social estão presentes" (p.125).

\section{O preconceito como um dificultador de mudanças}

A entrevistada refere-se a dificuldades relacionadas à manutenção dos adolescentes na escola e mesmo à necessidade de se fazer um treinamento dos conveniados que os recebem para prestação de serviços. Isso além de revelar uma dificuldade no sentido de falta de locais para onde encaminhá-los, traz embutida uma situação de preconceito. Numa fala da entrevistada consta: "Não adianta encaminhar e a pessoa falar: 'Ai que saco, receber esse menino aqui, esse trombadinha, esse menino que vai pegar a minha bolsa"."

Relacionado ao preconceito, Sawaia (2001), ressalta duas idéias fundamentais. Segundo ela, a primeira, de Mello, apresenta uma dramática análise da violência cometida contra jovens das camadas populares, na cidade de São Paulo, apontando que a impunidade que acoberta tais crimes é um fator a mais na sustentação da exclusão nas grandes metrópoles, com apoio da mídia, que cria e divulga estereótipos estigmatizadores dessa população. A segunda idéia é de Pedrinho Guareschi, o qual dá início ao seu estudo discutindo as razões históricas da prevalência da exclusão na atualidade e mostra alguns pressupostos psicossociais significativamente ideológicos que permitem sua legitimação e perpetuação, dando ênfase aos mecanismos de competitividade entre os indivíduos e de sua culpabilização. Portanto, trabalhar com esses adolescentes é também enfrentar os estigmas, os preconceitos que sobre eles recaem e colocá-los no mercado de trabalho, muitas vezes é uma tarefa difícil, inviabilizando mudanças na sua situação de excluídos.

Nesse sentido, como conseguir aquilo que defende Waiselfisz (1998), que é o desenvolvimento da autodisciplina e autocontrole a partir de um conjunto de valores éticos e universais? Se esse adolescente não se vê reconhecido como sujeito, merecedor de respeito e confiança, como ocorrerá esse processo? Para Waiselfisz (1998), esse fato seria de vital importância. Diz ele que de maneira paradoxal observa-se grande lacuna nas agências e nos órgãos encarregados de fomentar e desenvolver a segurança, o fortalecimento da identidade e os compromissos dos jovens para com a sociedade. 


\section{Reincidência - o resultado do sistema emperrado (ou o resultado da não mudança)}

Sem lograr êxito nessas tentativas de mudança, muitas vezes o jovem reincide nos atos infracionais e continua se enveredando por essa vida de um ato atrás do outro, sem perspectiva de mudanças, chegando mesmo a "atingir a maioridade na unidade de internação", conforme refere a entrevistada. Essa é uma questão que ocupa páginas de jornal e os noticiários inúmeras vezes, pois é sabido que a falha institucional de não propiciar mudanças, mas sim acabar sendo uma escola do crime, acaba mantendo os jovens institucionalizados. O mais grave muitas vezes é que, de lá saindo, fazem uma ponte direta para o sistema carcerário dos maiores de idade, como é o caso de alguns dos jovens que se envolveram nos crimes de espancamentos até a morte de outros jovens.

Ademais, talvez seja o caso de se questionar até que ponto as medidas têm sido realmente sócio-educativas, uma vez que a entrevistada refere: “... quando o adolescente chega até a minha seção, quando pratica um furto e olhamos a passagem anterior, se ele tiver, trata-se de um outro furto. São geralmente crimes contra o patrimônio". Então, há que se pensar: as falhas são da instituição ou são do próprio sistema que não oferece oportunidades a esses adolescentes? E o sistema familiar, como está nessa situação, qual a sua parcela nessa reincidência? A reincidência, certamente gera um sentimento de impotência em todos os envolvidos - família, sistema jurídico e social e até ao adolescente, muitas vezes. Com certeza, a ação maior deveria ser preventiva e sabe-se que no ciclo vicioso de agir em cima da demanda que já cometeu o ato infracional, sem se ter recursos e pessoal para investir em ações diferenciadas, em geral não se consegue investir em prevenção.

\section{Conclusão}

Esse trabalho possibilitou-nos perceber as possíveis interfaces entre as teorias em Psicologia Social e sua interface com a prática jurídica. Os resultados encontrados apontam para uma mudança na forma de falar sobre o adolescente autor de ato infracional e a tentativa de tratá-lo de acordo com esse novo paradigma, que foge da compreensão dicotômica do adolescente enquanto vítima ou enquanto algoz. Mas, as inúmeras dificuldades e limitações apontadas nos resultados sugerem a dificuldade de uma prática coerente com esse novo discurso que se constrói sobre essa clientela. Uma das dificuldades percebida é que a deficiência de recursos institucionais, tanto humanos quanto financeiros, na Vara da Infância e Juventude 
e, sobretudo, na Secretaria de Ação Social, impossibilitando as ações almeja. Acredita-se que muitas vezes, as reincidências podem estar ocorrendo em função dessas falhas no sistema, as quais não vêm propiciando as mudanças desejadas.

Sem dúvida alguma, ainda se fazem necessárias muitas pesquisas que alcancem esse tema em profundidade, a fim de que possamos discutir melhor a prática dos profissionais que atuam com os adolescentes autores de ato infracional e suas famílias. Um possível tema também a se investigar seria relacionado às ações preventivas com os adolescentes, o que foge ao trabalho da SEMSE que trata apenas das medidas previstas em lei a serem aplicadas àqueles que já cometeram atos infracionais. Entretanto, ainda com essas medidas talvez seja possível agir preventivamente, em relação à reincidência, uma questão preocupante conforme foi citado.

\section{Referências}

ALTHUSSER, L. (1974). Ideologia e aparelhos ideológicos do estado. Trad. J. J. M. Ramos. Portugal: Presença/Brasil: Martins Fontes.

BERGER,P.L. E LUCKMANN, T. (1996). A construção da realidade social. Petrópolis/ Rio de Janeiro. Ed. Vozes.

BUCHER, J. F. (1992). Lei, transgressões, famílias e instituições: elementos para uma reflexão sistêmica. Psicologia: Teoria e Pesquisa, 8, Suplemento, pp. 475-483. Brasília: UnB.

CINNANTI,C.J.J. (1999). Redes Sociais na prevenção da drogadição entre crianças e adolescentes em situação de rua. Em: D.B.B. de Carvalho; M.T. da Silva (Orgs.), Prevenindo a drogadição entre crianças e adolescentes em situação de rua (pp. 65-78). Brasília: MS/COSAM; UnB/PRODEQUI; UNDCP.

DEMO, P. (1991). Assistência Social como direito de cidadania. DME/SAE (apostila).

GONZÁLEZ REY, F. (1997). Epistemología Cualitativa y Subjetividad. Ciudad de La Habana: Ed. Pueblo y Educación.

GONZÁLEZ REY, F. (1999). La investigación cualitativa en Psicología. Rumbos y desafíos. São Paulo: EDUC.

LANE, S.T.M. (1984). O processo grupal. Em S. T. M. Lane; W. Codo (Orgs.), Psicologia Social. O homem em movimento (pp. 78-98). São Paulo: Ed. Brasiliense.

MACHADO, M.S.K. (1997). Os meninos de rua do eixo monumental. Em: B.F. Nunes (org.) Brasília: a construção do cotidiano. Brasília: Paralelo 15.

MAGAGNIN, A.T. (1999). A construção do significado da violência pelos adolescentes de Brasília. Brasília: UnB / Instituto de Psicologia.

MICHAUD, Y. (1989). A violência. São Paulo: Ática. 
MINAYO, M.C. de S. (1996). O Desafio do Conhecimento. Pesquisa Qualitativa em Saúde. São Paulo: HUCITEC-ABRASCO, $4^{\text {a }}$ Ed.

PACKMAN, M. (1993). Terapia familiar em contextos de pobreza, violência e dissonância étnica. Nova Perspectiva Sistêmica, 4: 8-19.

PORTO, M.S.G. (2000). A violência - entre a inclusão e a exclusão social. Tempo Social, Revista Sociológica. USP, São Paulo, 12/1: 187-200.

REIS, J. R. T. (1984). Família, emoção e ideologia. Em S.T.M. Lane; W. Codo. (Orgs.), Psicologia Social. O homem em movimento. (pp.99-124).São Paulo: Ed. Brasiliense.

RODRIGUES, E.G. (2000). As crianças e os adolescentes assistidos pela FSS/DF. Em: ALMEIDA, A.M.O. e PULINO, L.H.C.Z.. (orgs.). Projeto Bem-me-quer: Fórum de combate à violência (pp.47-56). Cadernos do PROPEM, 1. Brasília: Prática.

SAWAIA, B.B. (2000). As artimanhas da exclusão - análise psicossocial e ética da desigualdade social. Petrópolis: Vozes, $3^{\text {a }} \mathrm{Ed}$.

SILVA NETO, N.A. (2000). A Psicologia e a Violência: Sobre concepções e Instrumentos. Em: ALMEIDA, A.M.O. e PULINO, L.H.C.Z.. (orgs.). Projeto Bem-me-quer: Fórum de combate à violência (pp.87-92). Cadernos do PROPEM, 1. Brasília: Prática.

VOLPI, M. (2000). A experiência de privação de liberdade na percepção dos adolescentes em conflito com a lei. Dissertação de mestrado em Política Social. Universidade de Brasília, Brasília.

WAISELFSZ, J.J. (1998). Juventude, violência e cidadania: os jovens de Brasília. São Paulo: Cortez Ed.

WERTHEIN, J. (2000). Juventude, Violência e Cidadania. Em: ALMEIDA, A.M.O. e PULINO, L.H.C.Z.. (org.). Projeto Bem-me-quer: Fórum de combate à violência. Cadernos do PROPEM, 1, (pp.47-56) . Brasília: Prática.

WIEVIORKA, M. (1997). O novo paradigma da violência. Tempo Social, Revista Sociológica. USP, São Paulo, 9(1): 5-41. 


\section{ANEXO I}

\section{Roteiro de Entrevista}

1. Qual o caminho que o adolescente autor de infracional, percorre até a Vara da Infância e da Juventude?

2. Que medidas socioeducativas são adotadas em relação a ele?

3. Quais os adolescentes autores de ato infracional que recebem intervenção da Vara da Infância e Juventude?

4. Quais os projetos implementados pela equipe para atuar junto a esses adolescentes?

5. Qual a formação dos integrantes da equipe da SEMSE que atua junto aos adolescentes autores de ato infracional?

6. Qual a função do psicólogo, nesses projetos, junto ao adolescente?

7. A Vara da Infância tem algum projeto voltado para as famílias desses adolescentes?

8. Existe um alto índice de rejeição por parte da família, em relação ao adolescente infrator?

9. Qual a atuação do órgão com relação à família que rejeita o infrator?

10. Qual o índice de retorno desses adolescentes à Vara?

11. As infrações são as mesmas?

12. Quais as possibilidades de encaminhamento desses adolescentes? 